\title{
AUTORREGULAÇÃO JURÍDICA NO URBANISMO CONTEMPORÂNEO: SMART CITIES E MOBILIDADE URBANA
}

\section{SELF REGULATION IN THE CONTEMPORARY URBANISM: SMART CITIES AND URBAN MOBILITY}

\author{
Patrícia Borba Vilar Guimarães ${ }^{1}$ \\ Lucas do Monte Silva²
}

\begin{abstract}
Resumo
A presente pesquisa teve como objetivo analisar a relação entre a mobilidade urbana, a economia colaborativa e a possibilidade de autorregulação jurídica, no contexto das smart cities. Tais temas convergem com a tendência atual do direito à cidade e da adoção de novas tecnologias para facilitar a vida dos cidadãos. O método de procedimento adotado foi o hipotético-dedutivo. Conclui-se que o conceito urbanístico de smart city ultrapassa a caracterização até então conhecida de cidade sustentável, como preconizado pelo Estatuto da Cidade. Sua caracterização requer, para além do componente da valorização da proteção ambiental, o uso de tecnologias digitais para a melhoria e oferta de serviços públicos eficientes, cujo monopólio sai das mãos da administração pública e é gerido também pela população, de forma empreendedora e espontânea, e que participa ativamente desse processo de oferta de bens e serviços públicos de interesse coletivo.
\end{abstract}

Palavras-chave: Smart cities. Mobilidade urbana. Economia colaborativa. Autorregulação. Direito à cidade.

\section{Abstract}

This study aimed to analyze the relationship between urban mobility, collaborative economy and the possibility of legal self regulation in the context of smart cities. These themes converge with the current trend of the right to the city and the adoption of new technologies to make life easier for citizens. The method adopted was the hypothetical-deductive. We conclude that the urban concept of smart city exceeds the characterization hitherto known sustainable city, as recommended by the City Statute. Characterization requires, in addition to environmental protection enhancement component, the use of digital technologies for the improvement and provision of efficient public services, whose monopoly out of the hands of government and is also managed by the population, entrepreneurial and spontaneously, and actively participates in this bidding process of public goods and services of collective interest.

Keywords: Smart cities. Urban mobility. Sharing economy. Self regulation. Right to city.

\footnotetext{
${ }^{1}$ Doutora em Recursos Naturais pela Universidade Federal de Campina Grande. Professora Adjunta da Universidade Federal do Rio Grande do Norte. Líder da Base de pesquisa em Direito e Desenvolvimento. Email: patriciaborb@gmail.com

${ }^{2}$ Acadêmico do curso de Direito na Universidade Federal do Rio Grande do Norte (UFRN). Membro da Equipe Editorial da Revista Direito e Liberdade, publicada pela Escola da Magistratura do Rio Grande do Norte (ESMARN). E-mail: lucasdomonte1@gmail.com
} 


\section{INTRODUÇÃO}

No tradicional campo do Direito e da regulação das relações sociais e econômicas, uma abordagem da Ordem Econômica Constitucional, as associações teóricas e conceituais em torno da Livre Iniciativa, do Desenvolvimento Sustentável e do respeito ao meio ambiente são comuns. No mesmo sentido, a caraterização constitucional dos Direitos Sociais, inclusive ao transporte e à boa qualidade de vida nas cidades possui vasta exploração doutrinária e jurisprudencial. Entretanto, as sociedades contemporâneas vêm sendo notabilizadas por interações econômicas que requerem abordagens jurídicas diferenciadas, típicas de momentos de transição paradigmática.

A tendência mundial é que a gestão das cidades, com auxílio de novas tecnologias, consiga cada vez mais se modernizar, de forma a facilitar as relações entre os cidadãos e os administrados, bem como contribuir para a melhoria do cotidiano. Alinhado a esse quadro está o fenômeno da economia colaborativa ou compartilhada ou ainda, sharing economy. Autores que preconizam esse modelo como RIFKIN (2014b), apontam a emergência de uma economia de custo marginal tendente à zero, numa abordagem colaborativa entre as pessoas, na qual a tecnologia intensiva no seu uso, a Internet das Coisas, o Big Data e milhões de pessoas usando a internet e redes sociais para compartilhar carros, casas, roupas, ferramentas, roupas e outros itens já são uma realidade que movimenta bilhões de dólares.

Embora não haja um conceito fixo e determinado para esse modelo de trocas pessoais, pode-se conectá-lo à utilização de novas tecnologias para servirem como plataforma e facilitarem a realização da comunicação e negócios, e cuja principal característica é que nem sempre o lucro financeiro é o elemento preponderante.

Metodologicamente, é nesse contexto que se tangencia o objetivo inovador e a relevância dessa análise, do ponto de vista jurídico, sobre como podem ser realizadas eventuais políticas públicas nas quais os modelos de trocas colaborativas já atuam livremente, e como o Estado pode atuar ou abster-se na regulação de uma cada vez mais complexa rede de pessoas e informações nos meios urbanos, em busca de melhores condições de vida e bem estar, abrindo espaço para a caracterização de cidades inteligentes ou smart cities, com base em categorias originalmente tratadas em separado pelo universo do Direito, estanques, e que necessitam novas abordagens que favoreçam o diálogo com a economia e permitam o alcance de novas situações e fatos da vida das pessoas nos grandes centros urbanos. 
Esse texto tem como objetivos específicos apresentar uma discussão sobre as seguintes questões de pesquisa, as quais se influenciam reciprocamente: (i) Quais as demandas de tratamento jurídico presentes nos conceitos de smart city e mobilidade urbana?; (ii) Qual a relação entre a economia colaborativa e a mobilidade urbana?; (iii) Como vem sendo regulada a economia colaborativa, seja no campo da regulação estatal ou autorregulação?; (iv) Quais são os parâmetros legais ora estabelecidos para inovadores empreendimentos de mobilidade urbana no contexto da economia colaborativa no Brasil?.

Para responder esses questionamentos, utilizou-se da pesquisa bibliográfica e do método hipotético-dedutivo, com o objetivo geral de verificar e analisar formatos de regulação para a economia colaborativa, segundo um novo conceito urbanístico das smart cities, a partir de experiências inovadoras de mobilidade urbana no Brasil.

O artigo se divide em três momentos. Na primeira seção, serão analisados os conceitos de smart city, sustentabilidade e mobilidade urbana e a sua relação com o Direito, investigando como e de que modo essa conexão pode ser verificada e é influenciada.

Em seguida, discutem-se parâmetros e modelos de como vem sendo regulada a mobilidade urbana no ambiente da economia colaborativa, fundamento de empreendimentos como o Uber e o Airbnb, na atualidade. Analisam-se possibilidades de autorregulação e hipóteses de adoção de um modelo jurídico autoregulativo para experiências de mobilidade urbana colaborativa, baseada em aplicativos e softwares informacionais. Investigam-se situações de uma regulação estatal adequada para estabelecer os parâmetros dessa nova plataforma de mobilidade urbana.

Por fim, na terceira seção, analisa-se, na forma de estudo de caso, a empresa Uber, que vem ganhando destaque mundial na indústria da economia colaborativa. Nesse contexto, apresenta-se o marco regulatório da cidade de São Paulo no que se refere à mobilidade urbana, o recém-promulgado Decreto № 56981/2016-SP.

\section{O CONCEITO DE SMART CITYNO CAMPO JURÍDICO URBANÍSTICO BRASILEIRO}

\section{Smart city no direito brasileiro: aproximações conceituais e possibilidades}

Há um consenso na literatura especializada não jurídica, de que ainda não há unidade terminológica nem conceitual acerca do uso da palavra smart city, ou cidade inteligente - essa é a sua tradução comum para a língua portuguesa - fato que reflete de certa maneira a complexidade 
do próprio uso. Não obstante este fato, o termo smart city vem sendo cada mais utilizado como uma expressão contemporânea do ideal urbanístico que agrega boa qualidade de vida, comunicação e gestão eficiente dos serviços e espaços púbicos, proteção do meio ambiente, ou seja, uma cidade sustentável, numa primeira vista, conforme a utilização da expressão por analogia dos termos dos mais recentes ordenamentos urbanísticos brasileiros. Mas a cidade inteligente parece ser mais do que isso.

A smart city é vista muito mais como um fenômeno atual do urbanismo, um modo de viver, de amplo uso tecnológico e ampliação de valores culturais, caracterizado pela ampla inserção cidadã dos indivíduos no espaço da cidade onde vive e realiza as suas atividades cotidianas, com o atendimento pleno das suas necessidades de habitar, locomover-se, trabalhar, comunicar-se e se relacionar com o meio ambiente, com a maior eficiência e qualidade de vida possível.

Torna-se importante distinguir algumas possibilidades e fixar parâmetros mínimos orientativos que permitam a análise e discussão desse fenômeno urbanístico no mundo do Direito, uma vez que o seu enfrentamento compreende fatos sociais importantes e seu contexto abarca a tutela de bens jurídicos fundamentais, tanto no campo público quanto privado, e, especialmente num espaço de intersecção entre esses dois mundos tradicionais do Direito, atualmente considerados de tênue diferenciação no exame das situações concretas.

A literatura estrangeira é farta de explorações do termo smart city, claramente associado ao urbanismo contemporâneo e aos fenômenos da existência de comunidades baseadas em respeito ao meio ambiente, uso intensivo da tecnologia da informação e respeito ao desenvolvimento humano e social, a partir do modo de habitar e conviver nas cidades. Em linhas gerais, se traduziria o uso do termo smart city em experiências urbanas de agregação e aplicação simbiótica de princípios: (i) ambientais; (ii) de inovação tecnológica e comunicação digital; e (iii) do desenvolvimento humano a partir de uma visão holística.

Várias políticas públicas e desdobramentos legislativos diversos, além de programas e financiamentos específicos têm sido ofertados, em especial nos países desenvolvidos, no sentido de proporcionar aos cidadãos a experiência da cidade inteligente, eco-eficiente, digitalmente inclusiva e participativa, visando em geral modelos de desenvolvimento onde o pensar e planejar localmente o espaço tem grande relevância.

Temas como: governança, sociedade, mobilidade urbana, dados e tecnologia, sustentabilidade, uso com finalidade pública das redes sociais, economia e suas variações, como economia criativa, economia circular, economia colaborativa, estão no palco em torno desse tema 
e são considerados condicionantes dos processos de configuração de ambientes urbanos nesse contexto de visão.

O fenômeno da comunidade inteligente está ligado diretamente a ideia de espaço, uma vez que pode estar representado num bairro, cidade, estado, país ou região bem delimitada e caracterizada como digitalmente e socialmente inteligente e ecologicamente sustentável.

Cocchia (2014) realizou uma das mais extensas revisões de literatura acerca dessa terminologia, apontando que o uso remonta a aproximadamente 20 anos, tendo realizado estudo que compreendeu de 1993 a 2012, e que caracterizou algumas diferenciações a partir do termo "smart" e do seu significado, daí os usos: inteligente, do conhecimento, ubíquo, sustentável, digital, etc. A construção acadêmica do termo foi depreendida pelo mesmo autor, que investigou amplamente as citações e aproximações conceituais que seu uso possibilitam. Há, entretanto consenso em torno da ideia de que a cidade, a cidade inteligente, por consequência, se constrói a partir da gestão eficiente e dos mecanismos de controle e governança, categoria na qual o Direito é elemento central da conformação da cidade e da consequente ideia de cidadania.

\section{A governança para as smart cities: regulação e urbanismo na sociedade digital}

Ao tomarmos como referência os princípios pelos quais se define uma smart city, seria interessante definirem-se dimensões de bens jurídicos tutelados, de modo a perceber as variáveis que interferem na sua configuração. Questões como: transporte/mobilidade, aplicações da tecnologia digital, proteção dos recursos naturais, fomento ao lazer e cultura, moradia, formas do exercício da atividade econômica e do trabalho, inclusão social são parâmetros importantes na configuração da cidade inteligente.

Nesse aspecto, a simples enumeração de direitos, não é suficiente. Entretanto, a governança pública e a forma de controle e proteção dos direitos de cidadania adquire bastante relevância para a configuração de uma cidade socialmente inteligente.

A smart city grega valores diversificados, mas intimamente ligados à ideia de bem estar, pois ao contrário das cidades tradicionais, a cidade inteligente está baseada na boa qualidade de vida, prosperidade e produtividade, caracterizada como um espaço urbano provido de infraestruturas de tecnologia de informação e comunicação inteligente, em serviço do meio ambiente, governança, espaços e serviços públicos, elementos que podem caracterizar a noção ampliada do direito à cidade na contemporaneidade. 
O direito à cidade no Brasil tem sido um espaço jurídico importante de expansão das liberdades públicas em torno do ideal de realização plena da cidadania. O Estatuto da Cidade veio a preencher um espaço de regulamentação significativo, mas que ainda não permite a garantia plena da configuração de uma cidade inteligente, passados alguns anos da sua edição. é natural que, com a aquisição de novas experiências de vida urbana, a atividade interpretativa do Direito também seja demandada em torno de novos conceitos e problemáticas coletivas, carentes de regulamentação. Entretanto, é da combinação de estatutos diversificados no direito brasileiro mediante a base interpretativa constitucional integrativa que podemos pensar numa proteção ampla dos novos fenômenos urbanos.

Dentre os aspectos que causam maiores obstáculos à plena aquisição dessa ampla cidadania urbana está a mobilidade, categoria ínsita ao que se pode denominar direito à cidade, mas que não encontra efetividade para além do texto meramente taxativo do direito ao transporte público enumerado na Constituição e regulamentado pela Lei Federal n. 12.587/2012, a Lei da Política Nacional de Mobilidade Urbana (PNMU), que, por sua vez, remete ao Estatuto da Cidade.

A sociedade e o direito têm experimentado valores novos, trazidos pela profusão de aplicativos e mídias sociais que trouxeram novas possibilidades para o atendimento de demandas privadas que tangenciam, com bastante criatividade e respostas inovativas, o espaço público, ou tradicionalmente de atuação estatal.

A mobilidade urbana, a partir de experiências colaborativas como os serviços Uber e Waze, dentro outros casos de aplicativos desenvolvidos com base na ideia de interação entre as pessoas, são exemplos dessa nova conformação. Evidente que o direito precisa atualizar-se e reinventar-se para dar conta dessas novas relações, que passam a caracterizar o novo espaço público da cidade e dos seus desdobramentos coletivos, inclusive para permitir um posicionamento econômico do país consentâneo com o restante do mundo. A regulação jurídico-econômica passa a requerer novos contornos, em especial nos grandes espaços urbanos.

\section{ECONOMIA COLABORATIVA E AUTORREGULAÇÃO JURÍDICA: POSSIBILIDADES NO CAMPO DA MOBILIDADE URBANA}

\section{Economia colaborativa e mobilidade urbana}

Como visto na seção anterior, não há um conceito homogêneo de smart cities, tampouco um critério claro que possa diferenciar uma city de uma smart city (COCCHIA, 2014). Estas usam a

Revista de Direito da Cidade, vol. 08, no 4. ISSN 2317-7721 pp. 1231- $1253 \quad 1236$ 
tecnologia para melhorar a qualidade de vida dos cidadãos e indiretamente prover uma maior proteção ao meio ambiente. Tal critério não é suficiente para um estudo abrangente sobre o tema.

Diversos municípios no Brasil já utilizam da tecnologia para auxiliar o serviço público, como, por exemplo, a possibilidade da população participar no Orçamento Participativo Digital, a emissão de diversos documentos por via online, o uso de câmeras para promover melhor segurança para os cidadãos. Seriam elas smart cities apenas por esse critério? Acredita-se que não.

A transformação em uma smart city não é uma escolha do Poder Público. Trata-se de um conjunto de ações, iniciativas e projetos, tanto do Poder Público quanto da iniciativa privada, na modernização da cidade. Por isso, um critério unificador não seria recomendável. Acredita-se que uma cidade litorânea não deve possuir o mesmo critério classificatório de uma cidade da zona industrial, em se tratando da configuração de uma cidade inteligente. Os modelos possíveis são dependentes de cada contexto e das potencialidades locais. A estratégia 2020 da Europa - a maior e mais bem-sucedida comunidade econômica que conhecemos - baseia-se em três elementos: crescimento inteligente, baseado na inovação tecnológica; crescimento sustentável, baseado no cuidado ecológico e; crescimento inclusivo, favorecendo "uma economia com níveis elevados de emprego que assegura a coesão econômica, social e territorial" (COMISSÃO EUROPEIA, 2016).

Mas, então, o que torna uma cidade inteligente? Embora não seja possa definir de forma clara o emprego do termo, pode-se apresentar três aspectos que podem ser vistos como notas caracterizadores das smart cities: eficácia na gestão, valorização do escopo ambiental e inovação tecnológica para a melhoria dos serviços públicos.

Desse modo, uma cidade inteligente não se limita a ideia de uma "cidade digital" (digital city), indo além, albergando outras dimensões, como o aspecto ambiental e a promoção de um ambiente propício à inovação (SILVA; GUIMARAES, 2015). Nesse sentido, Giffinger et al (2007) elenca seis dimensões diferentes de uma smart city: smart mobility, smart environment, smart people, smart living, smart governance, smart economy. O enfoque da presente pesquisa será o primeiro aspecto: smart mobility.

A smart city não é um fim em si mesmo. Toda a modernização do espaço urbanístico deve ter como enfoque o interesse público. Busca-se, por meio do grande número de informações que circulam, provenientes de diversos sensores e pessoas, resolver problemas, sejam eles novos ou antigos (TOWNSEND, 2013, p. 12). Essas informações já existem, o que falta é um planejamento e um rede colaborativa para que essas informações sejam compartilhadas com outros. 
A determinação legal do Estatuto da Cidade traz a seguinte dicção, em seu artigo 2ㅡ, no tocante à caracterização e definição de objetivos de política urbana, para "o pleno desenvolvimento das funções sociais da cidade e da propriedade urbana": "I - garantia do direito a cidades sustentáveis, entendido como o direito à terra urbana, à moradia, ao saneamento ambiental, à infraestrutura urbana, ao transporte e aos serviços públicos, ao trabalho e ao lazer, para as presentes e futuras gerações".

O imperativo do artigo citado, como tratamento meramente formal aqui enfrentado no nosso sistema de regulação jurídica, evidencia as limitações e complexidades do seu alcance sobre as problemáticas que a vida urbana alcança. Dentre elas, a mobilidade urbana. Vem à tona no artigo referido, o conceito de cidade sustentável, como aquela na qual, dentre outros, o direito ao transporte é garantido pelo Estado.

A crescente dinâmica populacional nas cidades, acrescida das facilidades proporcionadas pelas inovações tecnológicas, por sua vez, vêm a ocupar esse espaço de crise de gestão estatal, dando origem às mais diversas experiências colaborativas, nas quais os indivíduos preenchem através do empreendedorismo digital e da livre iniciativa - essa função tradicionalmente concedida ao Estado, trazendo serviços inovadores, que, sem dúvida, vem a contribuir para a construção mais eficiente e ambientalmente inteligente do espaço urbano e das necessidades públicas de conforto e bem estar.

No escopo da mobilidade urbana, serviços turísticos, do setor de serviços em geral, as economias locais têm inovado bastante, a partir dessas experiências baseadas em tecnologias digitais, sociais e informacionais para melhoria do bem-estar coletivo.

Exemplo disso é o aplicativo de trânsito e navegação Waze. O Waze é um aplicativo de trânsito e navegação baseado em uma comunidade, na qual cada motorista compartilha informações, em tempo real, sobre o local que está transitando, permitindo que outros economizem tempo e combustível. Imprevistos no trânsito e trocas de informações sobre eles sempre existiram. Acidentes, obras, interrupções, congestionamentos, dentre outros diversos aspectos do cotidiano do trânsito sempre foram do conhecimento dos condutores que passando pelo local de determinada obra ou acidente observaram a causa de determinado congestionamento, mas essas informações não eram compartilhadas com tanta facilidade e velocidade proporcionada pela tecnologia digital. O citado aplicativo permite que essas informações sejam compartilhadas de forma pública para que, assim, uma pessoa possa verificar se 
a rota até o seu trabalho tem algum congestionamento e, caso esteja, o próprio aplicativo oferece uma rota alternativa com menos trânsito, deforma espontânea e totalmente colaborativa.

A autonomia do indivíduo, a partir de experiências como essa, se reverte em serviço de utilidade pública, em benefício do interesse público e na melhoria das condições de mobilidade urbana. É esse o enfoque da smart mobility. Utilizar-se de informações para tomar decisões mais inteligentes e úteis socialmente.

A smart mobility e a economia colaborativa possuem uma estreita relação entre si, uma vez que ambas possuem efeitos recíprocos. A economia colaborativa vem ganhando atenção especial no contexto da mobilidade urbana com o crescimento exponencial de empresas como a Uber e a Lyft.

A ideia de compartilhar um bem não é recente, sobretudo quando se está discutindo sobre mobilidade urbana. Tendo em vista que adquirir um veículo ou pagar o transporte de um local para outro, de forma individual, através de Táxis, para parcela da população é um meio custoso, observa-se a existência de ônibus e metrôs que compartilham os custos desses meios de transporte, diminuindo os valores para cada indivíduo. Isso é clarividente quando se está discutindo sobre o meio de transporte aéreo. Enquanto o custo para fretar um jatinho de cinco lugares para se locomover entre o trecho Rio de Janeiro e São Paulo, ida e volta, custa entre 10 a 20 mil reais (VEJA, 2011), uma passagem no meio aéreo convencional custa de 200 a 400 reais, por pessoa (GOOGLE, 2016).

O que diferencia a economia colaborativa dessa ideia de compartilhamento de bens tradicional é que o primeiro se utiliza de novos meios de comunicação (internet) e novas tecnologias para facilitar a relação entre o sujeito que busca compartilhar algum bem ou serviço (oferta) e aquele que quer utilizar esse bem temporariamente (sem necessariamente comprá-lo). A palavra-chave dessa economia é a descentralização. Essa descentralização é fundamental no contexto de uma smart city. Tráfegos longo e lento, malha viária com diversos defeitos estruturais e a poluição dos automóveis são algumas das consequências do crescimento da frota de carros do Brasil, sem um planejamento municipal adequado (COHEN; KIETZMANN, 2014, p. 281).

A ideia de ser "proprietário" de um carro entra em decadência em prol do carshare (aluguel de carro por hora ou dias) e do uso de serviços como o fornecido pelo Uber. Os longos tráfegos e o alto valor exigido para os estacionamentos nas cidades mais populosas fazem com que a população busque novas soluções, tal como a citada (COHEN; KIETZMANN, 2014, p. 287). 
Nesse contexto, encontra-se a problemática que será discutida na próxima seção e, de forma mais aprofundada em relação ao Uber, na seção 4, qual seja, a regulação da economia colaborativa, cujo principal elemento é a valorização da autonomia individual para a oferta de serviços de utilidade pública ou coletiva.

\section{Regulação e autorregulação na economia colaborativa}

A atividade regulatória exige uma harmonização (BARRY; CARON, 2015, p. 72). Por um lado, devem-se impor regras para que direitos e garantias dos sujeitos envolvidos nos negócios tenham sua devida proteção (p. ex: os consumidores, empregados e a própria concorrência), bem como o Estado consiga tributar de maneira adequada e justa os novos serviços, mantendo seu equilíbrio financeiro e capacidade de prestar serviços públicos. Por outro, para a inovação prosperar há necessidade de uma liberdade, seja do ponto de científica, seja da perspectiva econômica, adequada a dinamicidade de novos mercados.

Na maioria dos casos, os parâmetros regulatórios impostos para atividades semelhantes não são satisfatórias ou adequadas para essas novas tecnologias (HORTON; ZECKHAUSER, 2016, p. 2). Não é razoável impor as regras aplicáveis aos táxis nos motoristas que se utilizam do Uber, da mesma forma que não é adequado impor as regras que são aplicadas em hotéis aos quartos e casas que estão disponíveis no Airbnb (COHEN; SUNDARARAJAN, 2015). É importante destacar a linha tênue, na economia colaborativa, entre a esfera pessoal e a profissional. Aplicar uma estrutura regulatória estabelecida para grandes empresas e profissionais em pessoas que utilizam das plataformas como forma de ganho complementar para renda mensal, acaba criando uma barreira de entrada para a economia colaborativa e para a inovação.

É diante desse contexto que a problemática sobre a regulação da economia colaborativa surge. Antes de discutir essa temática, relevante ressaltar que a regulação não é a "simples imposição de regras, mas a intervenção normatizadora do ambiente econômico, de modo a reduzir a liberdade ou indicar parâmetros de atuação que devem ser seguidos elos agentes do mercado ou por aqueles que exercem uma determinada atividade" (SANTOS, 2005, p. 146). A regulação não pode se perpetuar práticas de outrora já superadas, tolhendo o crescimento econômico e a inovação, sobretudo diante da globalização da economia, em que é necessária uma análise e um diagnóstico internacional sobre as práticas econômicas (ZULUAGA, 2016). 
Na discussão sobre a regulação dessas novas plataformas, emergem-se duas vertentes principais: (a) Aquela que defende que estes serviços devem se autorregular; e (b) A que defende a regulação estatal, com ou sem a participação da iniciativa privada.

Haufler (2003) conceitualiza a atividade regulatória em quatro categorias: (i) regulação tradicional (traditional regulation), (ii) corregulação (co-regulation), (iii) regulação por múltiplas partes interessadas (multi-stakeholder regulation) e (iv) autorregulação (industry self-regulation) (HAUFLER, 2003, p. 237-239).

Segundo a autora, a regulação tradicional é aquela criada, promulgada e fiscalizada pelo Estado, com ou sem auxílio de outros países. Esse tipo de regulação entrou em crise com a economia globalizada, uma vez que cada país começou a diminuir cada vez mais as exigências e parâmetros regulatórios para atrair investimentos internacionais (HAUFLER, 2003, p. 237).

Com isso, a corregulação ganhou apoio. Na corregulação, o Estado e a iniciativa privada, juntos, estabelecem as normas que guiaram os setores. Enquanto a iniciativa privada se responsabiliza por estabelecer os parâmetros e critérios regulatórios, o Estado aplicará as sanções, caso alguma empresa não se adeque e aja de acordo com essas normas (HAUFLER, 2003, p. 238).

Uma terceira forma de regulação é regulação por múltiplas partes interessadas. Nessa, participam a inciativa privada, Estado, sociedade civil, organizações não-governamentais, dentre outras, em busca de estabelecer um padrão para a indústria. Em regras, são normas de conduta que possuem relevância social, como as normas relativas ao meio ambiente, que, devido a relevância, são impostas por si mesmas para as empresas, com fundamentos em razões apresentadas pelos outros autores. O principal fiscalizador desse sistema de regulação é o consumidor, que irá escolher e comprar produtos das empresas que respeitem essas regras (HAUFLER, 2003, p. 238-239).

Por fim, tem-se a quarta categoria, a autorregulação. A autorregulação é um complexo de regras e processos de regulação que são criadas pelas próprias partes envolvidas nesse setor da economia que os aplica em relações internas (com os parceiros) e externas (com terceiros) (COHEN; SUNDARARAJAN, 2015). Nesse caso, o Estado delega a atribuição de regular e administrar o setor econômico às próprias empresas (ASHBY; CHUAN; HOFFMANN, 2004, p. 1), que fazem isso através de códigos de conduta, compliance, regulações e estabelecimento de padrões das indústrias (VOGEL, 2008, p. 262).

Essa espécie de regulação vem ganhando importância aliada a participação de sujeitos nãoestatais: as empresas, sociedade civil, especialistas, etc, na criação de parâmetros regulatórias de 
novas tecnologias, o que, antes da influência da economia globalizada, era uma tarefa, essencialmente, dos legisladores (VOGEL, 2008, p. 262)

Relevante destacar que autorregulação não é o mesmo que desregulação ou falta de regulação. Trata-se de uma opção estatal em transferir a responsabilidade de regular determinado setor a terceiros, ou à iniciativa privada (COHEN; SUNDARARAJAN, 2015, p. 116), partindo do pressuposto que estes são os mais adequados para criar regras e parâmetros para o setor (ASHBY; CHUAN; HOFFMANN, 2004, p. 3).

A autorregulação é um novo paradigma do direito, que se baseia na autopoiese dos atores sociais (LISBOIS, 1998, p. 25). Nesse sentido, Lisbois (1998, p. 26) destaca que: “a autorregulação é, então, concebida como um método para resolver os problemas funcionais da regulação tradicional, como parte de uma reestruturação das formas e objetivos de intervenção legal".

Há uma tendência atual no sentido do amadurecimento do pluralismo jurídico, indo além do direito oficial, valorizando direitos constituídos paralelos e subjacentes a eles, como regulamentos, convenções e tratados (FARIA, 2002, p. 157). Nesse sentido, acabam ocorrendo gradativas "substituições do caráter centrípeto das estruturas socioeconômicas por um caráter essencialmente centrífugo, que esvazia a hierarquia como princípio de ordem" e, com isso, "acelera a conversão da sociedade contemporânea num intrincado conjunto de sistemas plurifinalistas e policêntricos (FARIA, 2002, p. 180).

Essa nova espécie de marco regulatório é um reflexo do direito responsivo, reflexivo ou relacional, baseando em normas que podem ser utilizadas a depender das circunstâncias, autonomia de cada organização e suas particularidades da cadeia produtiva (FARIA, 2002, p. 185), considerando a complexidade dos conflitos contemporâneos e a lentidão da capacidade de recepção, processamento e decisão nos sistemas estatais. Com isso, a sociedade cria sistemas parcialmente autônomos "cada um deles numa área determinada, organizando suas próprias estruturas, definindo sua própria racionalidade e padrões de legitimidade, produzindo suas próprias normas e seus respectivos procedimentos, regulando suas próprias operações e autoconstituindo sua identidade" (FARIA, 2002, p. 179).

A autorregulação já é uma realidade na maioria dos serviços da economia colaborativa (ALLEN; BERG, 2014, p. 22). Exemplo disso é o uso de mecanismos de avaliação e reputação de cada sujeito/bem ou serviço, uma vez que um ponto central desse tipo de economia é a confiança, tanto na qualidade do serviço, quanto na própria garantia dos seus direitos. Motoristas mal avaliados ou estadias mal pontuadas podem ser suspensas ou, até mesmo, excluídas das 
plataformas (SCHOR, 2014, p. 4). O mesmo ocorre com usuários mal avaliados pelos motoristas ou pelos hospedeiros.

Além disso, cada serviço impõe, mesmo que parcela significativa das exigências não sejam obrigações legais, determinados requisitos que devem ser preenchidos tanto pelo provedor de determinado serviço ou bem como pelo usuário da plataforma que necessita da realização dessas atividades. E, mesmo quando tais mecanismos não funcionam de forma adequada, as plataformas possuem planos de garantias, que embora semelhante, não utilizam o termo "seguro" para proteger os usuários de possíveis perdas e danos. A Airbnb (2016), por exemplo, oferece uma garantia de estadia no valor de até 1 milhão de dólares para cobrir eventuais danos. A Lyft (2016) empresa semelhante ao modelo de negócio da Uber - também oferece a cobertura do seguro de até 1 milhão de dólares por sinistro. Desse modo, a imposição de uma regulação estatal apenas obstaculizaria a expansão desses serviços, principalmente em países em desenvolvimento, nos quais a capacidade regulatória e de fiscalização estatal é diminuta, devido aos parcos recursos disponíveis para exercer seu mister (GRAHAM; WOODS, 2006).

Sobreleva notar, conforme pontuam Short e Toffel (2010, p. 27), que o ambiente jurídico possui importante função na autorregulação, sobretudo considerando que as normas provenientes das empresas seriam consideradas soft law (VOGEL, 2008, p. 264), de forma que a accountability provem da própria reputação da empresa no mercado, do que por meios formais, como a imposição de multas. Essa relação, todavia, é dinâmica. Uma norma criada pelas próprias empresas pode ser adotada e acolhida na esfera estatal, bem como as normas do Estado podem ser adotadas e possuir eficácia no mercado, sem a necessidade de constante fiscalização (VOGEL, 2008, p. 265). Além disso, não se pode olvidar que há diferenças entre regular as plataformas e regular as relações que se emergem a partir dela. Estas possuem maiores proporções e significância em cotejo com aquela, principalmente quando estão em jogo bens jurídicos de ordem pública, como a segurança jurídica, a integridade e a vida das pessoas (ZANITELLI, 2016).

Seria a autorregulação suficiente para regular esses novos setores? De acordo com a segunda corrente, a resposta é negativa. Segundo essa vertente que afirma ser necessária a regulação estatal, deve-se destacar a necessidade de promover uma concorrência leal com outros serviços, evitar o abuso de mercado, bem como corrigir ações irracionais do mercado.

A regulação estatal serviria como uma forma de assegurar os direitos dos usuários e a concorrência legal com outros serviços, estabelecendo os devidos parâmetros ao mercado de transporte de utilidade pública (AUSTRALIAN COMPETITION AND CONSUMER COMISSION, 2015). 
Autores como Posner (1974) enxergam a regulação econômica ao modo tradicional, ao se referir a "tributos e subsídios de todos os tipos, bem como aos controles legislativos e administrativos, expressos, sobre tarifas, entrada de novas empresas, e outras facetas da atividade econômica". A regulação estatal seria necessária para regular questões que a iniciativa privada, leia-se o mercado, não possui o interesse em gerir de forma satisfatória e adequada ao interesse público. Estaria essa visão superada pelas necessidades contemporâneas de serviços e utilidades públicas, em que os indivíduos possuem tanta autonomia quanto o mercado na solução dos problemas urbanos com o uso da tecnologia?

A título de exemplo, cita-se o caso O'Connor v. Uber, que é ação coletiva de motoristas contra o Uber. A principal discussão do caso cinge-se a discussão se os motoristas que utilizam a plataforma do Uber são prestadores de serviços ou empregados. Caso fossem considerados empregados, eles, nos Estados Unidos, teriam direito a reembolsos por despesas, incluindo combustível e manutenção do veículo, bem como gorjetas (UBER, 2015)

A Uber possui um interesse evidente nessa classificação, uma vez que afeta de forma direta seu modelo de negócio e, consequentemente, não poderiam ser reguladas de maneira satisfatória, do ponto de vista do interesse público e social, sendo necessária uma espécie de intervenção estatal, mesmo que não fosse pelos meios regulatórios usuais.

Não importando qual vertente possa ser considerada a mais adequada em cada contexto, é possível destacar dois consensos: (i) a regulação deve ser orgânica, sendo regulada de baixo para cima (bottom-up), isto é, autorregulada e, posteriormente, positivada em eventual legislação e, não, simplesmente imposta, de cima para baixo (top-down) por instrumentos de controles estatais, pois isso garante a sua legitimidade pelo processo democrático; (ii) necessidade de uma análise adequada sobre como deve ocorrer a tributação na economia colaborativa.

A regulação deve ser orgânica, pois, como visto, um marco regulatório estanque para estabelecer parâmetros de setores intimamente vinculados à inovação e que necessitam de respostas rápidas do Estado, em vez de estimular a inovação, estabelecerá óbices para os desenvolvimentos dessas novas tecnologias.

A tributação dessas relações econômicas merece mais atenção, uma vez que, depois da segurança dos bens e das relações jurídicas entre os sujeitos, é a primeira preocupação dos Estados, uma vez que impactará de forma direta a arrecadação pelo Fisco.

Buscando analisar as afirmações e argumentos apresentados nesta seção, analisar-se-á na próxima a regulamentação da mobilidade urbana, no contexto da economia colaborativa no Brasil.

Revista de Direito da Cidade, vol. 08, no 4. ISSN 2317-7721 pp. 1231- $1253 \quad 1244$ 
Como recorte dessa análise, optou-se pelo estudo de caso da empresa Uber, uma empresa que vem se expandido no mercado nacional, considerando que a cada cidade que o sistema da empresa é implementado, suscita-se conflitos e discussões sobre a possibilidade de sua regulação (ou não), bem como o modo que deve regulada. Por isso, diante sua importância nacional, justificase a necessidade de uma análise do tema na presente pesquisa.

\section{O CASO DA EMPRESA UBER: A REGULAMENTAÇÃO DA MOBILIDADE URBANA NO BRASIL}

\section{Conceituação e forma de funcionamento da Uber}

A empresa Uber é uma plataforma que conecta motoristas (pessoas que possuem carros e tempo disponível para transportar pessoas de um local para o outro, o que a Uber chama de "parceiros") com passageiros, através de um aplicativo de celular. O usuário, no aplicativo da empresa, solicita uma "corrida". A Uber verifica quais motoristas estão mais perto do local onde foi solicitado e o informa que uma pessoa solicitou uma corrida. Quando o motorista a aceita, o usuário possui acesso ao tempo estimado até que o motorista chegue ao local, bem como informa quando o motorista chegou. O usuário pode colocar o local de destino antes ou durante o trajeto. Ao chegar no local de destino, o valor da corrida é calculado e debitado automaticamente no cartão conectado a conta do Uber e o passageiro poderá avaliar a qualidade do serviço do motorista.

A Uber é apenas a plataforma que conecta esses dois indivíduos, fornecendo a plataforma para que isso ocorra e cobra, para tanto, $20 \%$ do valor da corrida. O motorista não é "empregado" da Uber e o carro utilizado não é propriedade da citada empresa, mas sim do próprio motorista. 0 "motorista", assim, são pessoas que possuem automóvel (que cumpre os requisitos da empresa) e tempo disponível para realizar o trajeto solicitado. Não há uma quantidade mínima de corridas diárias, semanais ou mensais para que permanece na plataforma.

Nesse caso, observam-se dois pontos que são vistos na economia colaborativa e podem ser compreendidos em outros serviços: a conveniência e a flexibilidade.

A conveniência é vista, sobretudo, pela perspectiva do usuário. No caso da Uber, por exemplo, este sabe que os motoristas e os carros utilizados pelo serviço preenchem determinados requisitos, como, por exemplo, o veículo ser novo (o ano do automóvel varia a depender da cidade), possuindo quatro portas, ar condicionado e cinco lugares; a carteira de motorista e o 
registro de licenciamento de veículo são válidos; que o motorista não possui antecedentes criminais etc. Além disso, o usuário poderá verificar a nota do motorista que foi dada por outros usuários.

A flexibilidade, por sua vez, é vista predominantemente do ponto de vista do motorista. A Uber não exige uma quantidade mínima de corridas ou que a pessoa esteja disponível em determinados horários, ou seja, uma habitualidade, como ocorre com um "empregado" normalmente. A pessoa, quando possuir tempo disponível e precisar de uma remuneração extra, pode habilitar a opção no seu celular e receber pedidos de corrida.

A conveniência e a flexibilidade são dois conceitos chaves na economia colaborativa, seja através de corridas (como no caso do Uber), seja através da locação de quartos e casas (Airbnb), ou qualquer tipo de bem ou serviço, e essas duas características reduzem os custos de transação.

\section{Regulamentação da mobilidade urbana no Brasil: 0 caso do Decreto $\mathrm{n}$ 은 $56981 / 2016$ de São Paulo}

No Brasil, a Uber está presente nas cidades de Belo Horizonte, Brasília, Campinas, Curitiba, Fortaleza, Goiânia, Guarulhos, Porto Alegre, Recife, Rio de Janeiro, Salvador, São Paulo, Campinas, Goiânia e Curitiba. Embora presente nessas localidades, são poucas onde o serviço já possui uma regulamentação específica para o tipo de transporte que realiza. Em sua maioria, ainda estão em discussão nas respectivas Câmaras Municipais projetos de lei que regulam o tema ou, em alguns casos, o proíbem simplesmente.

O Município de São Paulo, em maio de 2016, com fundamento nos arts. 12 e 18, I, da Lei Federal no 12.587, de 3 de janeiro de 2012 (Política Nacional de Mobilidade Urbana), regulamentou uso intensivo do viário urbano municipal para exploração de atividade econômica privada de transporte individual remunerado de passageiros de utilidade pública, o serviço de carona solidária e o compartilhamento de veículos sem condutor, por meio do Decreto no $56981 / 2016$.

Optou-se por analisar na forma de estudo de caso a regulamentação do Município de São Paulo por três motivos. Primeiro, o Município de São Paulo é o centro financeiro, corporativo e mercantil, não apenas do Brasil, mas da América do Sul. Segundo, esse Município possui a maior frota de veículos do Brasil. Terceiro, possui a regulamentação municipal brasileira mais avançada e específica para a economia colaborativa no que se refere à mobilidade urbana.

Revista de Direito da Cidade, vol. 08, no 4. ISSN 2317-7721 pp. 1231- $1253 \quad 1246$ 
O Decreto no 56981/2016, do Município de São Paulo, regulamentou três atividades de compartilhamento de veículo e uso intensivo do viário urbano municipal: (a) exploração de atividade econômica privada de transporte individual remunerado de passageiros de utilidade pública; (b) a carona solidária e (c) o compartilhamento de veículo sem condutor no Município.

Antes de analisar cada uma dessas atividades, cabe destacar as diretrizes de utilização e exploração do viário urbano municipal elencadas no art. 2o do Decreto ora em análise. Destaca-se, entre elas, a racionalização da ocupação e a utilização da infraestrutura instalada (inciso II); o incentivo o desenvolvimento de novas tecnologias que aperfeiçoem o uso dos recursos do sistema (inciso VI) e a harmornização com o estímulo ao uso do transporte público e meios alternativos de transporte individual (inciso VII).

Quanto ao transporte individual remunerado de passageiros (p. ex: Uber), o Decreto estabelece que as empresas que funcionam como plataformas tecnológicas, intermediando a relação entre os motoristas e os passageiros, devem ser credenciar como Operadores de Tecnologia de Transporte Credenciadas (OTTCs)(art. 5ㅇ).

As OTTCs possuem a competência, segundo o art. 6ㅇ e incisos do Decreto, de organizar a atividade e o serviço prestado pelos motoristas cadastrados, intermediando a conexão entre os usuários e os motoristas, mediante adoção de plataforma tecnológica. Dever cadastrar os veículos e motoristas prestadores dos serviços, atendidos os requisitos mínimos de segurança, conforto, higiene e qualidade e estabelecer a tarifa do serviço, observado o valor máximo estabelecido pelo Comitê Municipal de Uso do Viário (CMUV), disponibilizando meios eletrônicos para pagamento entre o usuário e o motorista, permitido o desconto da taxa de intermediação pactuada.

O Decreto no 56981/2016 estabelece alguns requisitos para a prestação do serviço ora em análise, como: a utilização de mapas digitais para acompanhamento do trajeto e do tráfego em tempo real; avaliação da qualidade do serviço pelos usuários; disponibilização eletrônica ao usuário da identificação do motorista com foto, do modelo do veículo e do número da placa de identificação; emissão de recibo eletrônico para o usuário, que contenham informações, como: a) origem e destino da viagem; b) tempo total e distância da viagem; c) mapa do trajeto percorrido conforme sistema de georreferenciamento; d) especificação dos itens do preço total pago; e) identificação do condutor.

Nesse ponto, cabe destacar que duas questões. Primeiro, nota-se que essa regulação estatal leva em consideração particularidades que já eram vistas como naturais na autorregulação, como, por exemplo, a exigência que o serviço permita a avaliação da qualidade do serviço pelos 
usuários e a emissão de recibo eletrônico para o usuário. Segundo, relevante salientar que essas exigências não são barreiras de entrada para eventuais concorrentes dos serviços existentes, uma vez que são requisitos mínimos facilmente implementáveis nas plataformas tecnológicas.

O Município de São Paulo estabeleceu uma política créditos de quilômetros para as OTTCS operarem. A utilização desses créditos, que serão contabilizados de acordo com a distância percorrida na prestação dos serviços pelos veículo, implica em outorga onerosa e pagamento de preço público como contrapartida do direito de uso intensivo do viário urbano (art. 8o).

Quanto à carona solidária (p. ex: BlaBlaCar), o Decreto permite o transporte individual não remunerado de condutores provedores de carona e passageiros interessados em compartilhar viagens e custos (art. 18ํ), desde que não seja exercido com profissionalismo; não tenha fins lucrativos e seja realizado por veículos particulares não utilizados para atividade econômica de transporte remunerado de passageiros.

Diferentemente do transporte individual remunerado de passageiros, para a intermediação da atividade de carona solidária no viário urbano não é necessário o pagamento de preço público por distância percorrida pelos veículos cadastrados (art. 199), sendo possível, no entanto, que a Prefeitura exija a cobrança de preço público mensal ou anual das OTTCs para se credenciarem perante esse ente federativo ( $\$ 20$, do art. 17).

Por fim, tem-se a possibilidade de compartilhamento de veículos sem condutor ( $p$. ex: Zaz Car), isto é, o serviço de locação de veículos em vagas de estacionamento em vias e logradouros público (art. 21, parágrafo único). A exploração desse serviço será condicionada ao pagamento de outorga pelo direito de uso de estacionamento em viário urbano, além de ser possível que a Prefeitura cobre preço público mensal ou anual das OTTCs para se credenciarem perante a citada Municipalidade (art. 22).

Como visto, a tentativa de regulação estatal do serviço Uber na maior cidade brasileira está pautada ora pelo controle e uso dos espaços públicos, ora pela tributação ou ainda, medidas de garantia da segurança dos usuários do serviço.

Na tentativa de construção de smart cities, sem dúvida experiências de smart mobility como o Uber estarão cada vez mais presentes. O critério da sustentabilidade é favorecido pelo transporte coletivo e colaborativo, o critério tecnológico está fortemente presente, cabendo ao direito a utilização de mecanismos que forneçam equilíbrio às relações sociais, sem, entretanto, tolher a capacidade humana individual, inventiva e criativa-empreendedora típica das cidades inteligentes. 


\section{CONCLUSÃO}

Esse trabalho teve como objetivo geral a investigação e discussão de algumas categorias de análise acerca dos delineamentos jurídicos para modelos de trocas colaborativas nas sociedades contemporâneas, e como o Estado pode atuar ou abster-se na sua regulação. Partiu do princípio de que os fenômenos urbanos têm se tornado cada vez mais complexos, com a adoção de modelos de trocas mais consentâneos com a tendência que caracteriza as smart cities, ou cidades inteligentes, nas quais a tecnologia, a eficiência na gestão dos recursos e serviços e a preocupação com o meio ambiente são os principais elementos, em busca de melhores condições de vida e bem estar coletivo.

Nesse sentido, partindo da hipótese de que há demandas de tratamento jurídico associadas ao conceito de smart city, relacionadas ao uso social da economia colaborativa, em especial observado no campo da mobilidade urbana, analisaram-se: a relação entre a economia colaborativa e a mobilidade urbana; como vem sendo regulada a economia colaborativa, seja no campo da regulação estatal ou autorregulação. Para tanto, identificaram-se alguns parâmetros legais ora estabelecidos para a mobilidade urbana no contexto da economia colaborativa no Brasil, com análise de caso sobre a regulamentação jurídica do aplicativo Uber.

Ficou evidenciado que o conceito urbanístico de smart city ultrapassa a caracterização até então conhecida de cidade sustentável, como preconizado pelo Estatuto da Cidade. Sua caracterização requer, para além do componente da valorização da proteção ambiental, o uso de tecnologias digitais para a melhoria e oferta de serviços públicos eficientes, cujo monopólio sai das mãos da administração pública e é gerido também pela população, de forma empreendedora e espontânea, e que participa ativamente desse processo de oferta de bens e serviços públicos de interesse coletivo.

A regulação jurídica das atividades que exigem maior liberdade nas relações de troca pessoais, portanto, passa por alterações de contornos que exigem rediscussão, dentro do natural e histórico movimento de retração e expansão do Estado, mercado e sociedade.

O que se observou no caso aqui analisado foi uma valorização da relação mercadosociedade, atuando nas lacunas do Estado, no que se refere ao atendimento de demandas pelo Direito ao transporte urbano de qualidade, abrindo espaço para a demanda da smart mobility como componente de uma smart city. 
O uso de aplicativos móveis, sites especializados e a presença de sujeitos dispostos a colaborar economicamente para a melhoria da oferta de serviços de transporte, com eficiência na gestão de recursos disponíveis e ganhos ambientais para a melhoria da mobilidade urbana é evidente e segue uma tendência mundial, onde a agregação de tecnologias sociais, ambientalismo e tecnologias digitais vai dar os contornos do novo urbanismo, o urbanismo inteligente.

\section{REFERÊNCIAS}

ABDOULAEVV, Azamat. A Smart World: A Development Model for Intelligent Cities. Anais. The 11th IEEE International Conference on Computer and Information Technology (CIT-2011). Cyprus, August, 2011.

AIRBNB. Guarantee. Disponível em: <https://www.airbnb.com/guarantee>. Acesso em: 30 maio 2016.

ALLEN, D.; BERG, C. The sharing economy: How over-regulation could destroy an economic revolution. Institute of Public Affair. December, 2014. Disponível em: <http://ipa.org.au/portal/uploads/Sharing_Economy_December_2014.pdf>. Acesso em: 25 maio 2016.

ASHBY, Simon; CHUAH, Swee Hoon; HOFFMANN, Robert. Industry Self-Regulation: A Game-Theoretic Typology of Strategic Voluntary Compliance. International Journal of the Economics of Business, v. 11, n. 1, p. 91-106, 2004

AUSTRALIAN COMPETITION AND CONSUMER COMISSION. The sharing economy and the Competition and Consumer Act. 2015. Disponível em: <https://www.accc.gov.au/system/files/Sharing\%20Economy\%20-\%20Deloitte\%20Report\%20\%202015.pdf $>$. Acesso em: 30 maio 2016.

BARRY, J. M.; CARON, P. L. Tax Regulation, Transportation Innovation, and the Sharing Economy. (December 15, 2014). University of Chicago Law Review Dialogue, v. 82, p. 69-84, 2015,

CHEN, Le; MISLOVE, Alan; WILSON, Christo. Peeking Beneath the Hood of Uber. Proceedings of the 2015 ACM Conference on Internet Measurement Conference, pp. 495-508.

CHEN, M.K; SHELDON, M. Dynamic Pricing in a Labor Market: Surge Pricing and Flexible Work on the Uber Platform. Disponivel em: $<$ http://www.anderson.ucla.edu/faculty/keith.chen/papers/SurgeAndFlexibleWork_WorkingPaper. pdf>. Acesso em: 12 jun. 2016.

COCCHIA, Annalisa. Smart and Digital City: A Systematic Literature Review. In: DAMERI, Renata Paola; ROSENTHAL-SABROUX, Camille (Eds.) Smart City: How to Create Public and Economic Value with High Technology in Urban Space. Springer: 2014. 
CODAGNONE, Cristiano; ABADIE, Fabienne; BIAGI, Federico. The Future of Work in the 'Sharing Economy'. Market Efficiency and Equitable Opportunities or Unfair Precarisation? (May 27, 2016). Science for Policy report by the Joint Research Centre, 2016.

COHEN, Boyd; KIETZMANN, Jan. Ride on! Mobility business models for the sharing economy. Organization \& Environment, v. 27, n. 3, p. 279-296, 2014.

COHEN, M.; SUNDARARAJAN, A. Self-Regulation and Innovation in the Peer-to-Peer Sharing Economy. U. Chi. L. Rev. Dialogue, v. 82, p. 116-133, 2015.

COMISSÃO EUROPEIA. Europa 2020. Disponível em: <http://eurlex.europa.eu/LexUriServ/LexUriServ.do?uri=COM:2010:2020:FIN:PT:PDF>. Acesso em: 20 jun 2016.

FARIA, José Eduardo. O direito na economia globalizada. São Paulo: Malheiros, 2002

GIFFINGER, R.; FERTNER, C.; KRAMAR, H.; KALASEK, R.; PICHLER-MILANOVI, N., e MEIJERS, E. (2007). Smart cities: ranking of European medium-sized cities. Centre of Regional Science (SRF). Vienna University of Technology, Vienna, Austria. Disponível em: <http://www.smartcities.eu/download/smart_cities_final_report.pdf>. Acesso em: 7 jan. 2016.

GOOGLE. Google Voos. Disponível em: <https://www.google.com.br/flights/>. Acesso em: 17 jun. 2016.

GRAHAM, David; WOODS, Ngaire. Making corporate self-regulation effective in developing countries. World Development, v. 34, n. 5, p. 868-883, 2006.

HAUFLER, Virginia. New forms of governance: certification regimes as social regulations of the global market. Social and political dimensions of forest certification, p. 237-247, 2003.

HORTON, J. J; ZECKHAUSER, R.J. Owning, Using and Renting: Some Simple Economics of the "Sharing Economy". 2016. NBER Working Paper n. 22029.

KERSHAW, D. Corporate Law and Self Regulation. LSE Law, Society and Economy Working Papers 5/2015. London School of Economics and Political Science.

LIBOIS, Boris. Autorégulation ou démocratisation?. Recherches en Communication, v. 9, n. 9, p. 2532, 1998.

LYFT. Safety. Disponível em: <https://www.lyft.com/safety>. Acesso em: 30 maio 2016.

MARS SOLUTIONS LAB. Shifting Perspectives: redesigning regulation for the sharing economy. Sharing Economy Public Design Report. 2016.

MELLO, Cláudio Ari. O futuro da mobilidade urbana e o caso Uber. Revista de Direito da Cidade, Rio de Janeiro, v. 8, n. 2, p.775-812, abr. 2016. 
MORENO, Juana Morcillo; MARTínEZ, Carmen María Fajardo. Política presupuestaria y discapacidad. Documentos de Trabajo. Seminario Permanente de Ciencias Sociales, n. 1, p. 1-24, 2013.

SILVA, Lucas do Monte; GUIMARÃES, Patricia Borba Vilar. Law and Innovation Policies: An Analysis of the Mismatch between Innovation Public Policies and Their Results in Brazil. Law and Development Review. v. 8, p. 1-56, 2015.

PARKER, Christine. Reducing the risk of policy failure: challenges for regulatory compliance: final version. OECD, 2000.

POSNER, Richard A. Theories of economic regulation. 1974.

RIFKIN, Jeremy. (2014b) The rise of anti-capitalism. The New York Times. March 15, 2014. Disponível em: <http://www.nytimes.com/2014/03/16/opinion/sunday/the-rise-of-anticapitalism.html?_r=1>. Acesso em 20 de junho. 2016.

RIFKIN, Jeremy. The Zero marginal cost society: The Internet of Things, the Collaborative Commons, and the Eclipse of Capitalism (2014a). Palgrave Macmillan: New York, 2014.

SANTOS, J.M. Visão Jurídica da Auto-Regulação. Revista de Previdência, Rio de Janeiro, n. 2, p. 153172, 2005.

SCHOR, Juliet. Debating the Sharing Economy. October 2014. A great transition initiative essay. Disponível em: $<$ http://www.geo.coop/sites/default/files/schor_debating_the_sharing_economy.pdf $>$. Acesso em: 27 maio 2016.

SHORT, Jodi L.; TOFFEL, Michael W. Making self-regulation more than merely symbolic: The critical role of the legal environment. Administrative Science Quarterly, v. 55, n. 3, p. 361-396, 2010.

TEUBNER, Timm; FLATH, Christoph M. The economics of multi-hop ride sharing. Business \& Information Systems Engineering, v. 57, n. 5, p. 311-324, 2015.

TOWNSEND, Anthony M. Smart cities: big data, civic hackers, and the quest for a new utopia. WW Norton \& Company, 2013.

UBER. A Few Facts About the O'Connor Court Case. Disponivel em: $<$ https://newsroom.uber.com/oconnorfacts/>. Acesso em: 20 jun. 2016.

VEJA. Voar de jatinho: uma questão de luxo e também de negócio. 2011. Disponível em: <http://veja.abril.com.br/noticia/economia/voar-de-jatinho-uma-questao-de-luxo-e-tambem-denegocio>. Acesso em: 17 jun. 2016.

VOGEL, David. Private global business regulation. Annu. Rev. Polit. Sci., v. 11, p. 261-282, 2008.

ZANITELLI, Leandro Martins. Usucapião e distribuição: breve análise da legislação brasileira. Revista Direito e Liberdade, Natal, v. 18, n. 1, p. 193-219, jan. /abr. 2016. Quadrimestral. 
ZULUAGA, D. Regulatory approaches to the sharing economy. Institute of Economic Affairs. Disponível em: <http://www.iea.org.uk/sites/default/files/publications/files/Regulating\%20the\%20sharing\%20eco nomy\%20Briefing\%202016.pdf>. Acesso em: 30 maio 2016.

Trabalho enviado em 21 de junho de 2016.

Aceito em 05 de agosto de 2016. 